Fostering a Learning Environment:

Coaches and the Motivational Climate

by

Justine B. Allen and Ken Hodge

Reprinted from

International Journal of

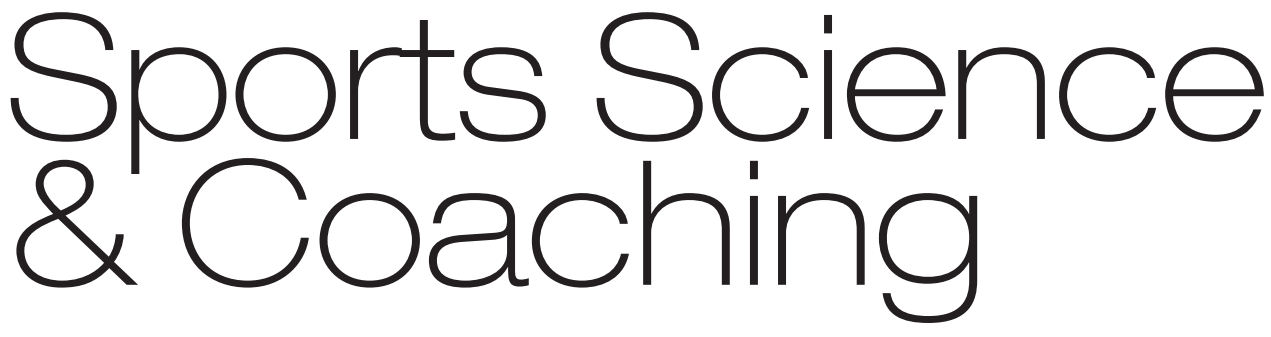

Volume 1 • Number 3 • 2006 


\title{
Fostering a Learning Environment: Coaches and the Motivational Climate
}

\author{
Justine B. Allen and Ken Hodge \\ School of Physical Education, University of Otago, \\ PO Box 56, Dunedin, New Zealand. E-mail: jallen@pooka.otago.ac.nz
}

\begin{abstract}
To foster athletes' learning and to continue to learn as a coach, it is useful to reflect on the motivational climate developed through the coaching process. The purpose of this paper is to provide a synthesis of research concerning the motivational climate fostered by coaches that extends existing notions of the motivational climate beyond competence-focused goals to include other athlete needs such as autonomy and relatedness. The paper brings together quantitative and qualitative research on coaching and examines both athletes' and coaches' perspectives relating to the motivational climate. Conceptualisations of the climate created by coaches have traditionally emphasised competence [1], but quality coaches also understand, support, and care for athletes as people [2]. In doing so, they can foster athletes' sense of autonomy and relatedness [3]. Satisfaction of these needs has been associated with an environment conducive to learning [4] and research demonstrates that coaches' practices are associated with the extent to which these needs are satisfied. $[3,5,6]$ The challenges and implications of this for coaches and researchers are discussed.
\end{abstract}

Key words: Autonomy, Competence, Goals, Motivation, Sport Coaching.

\section{INTRODUCTION}

The coach has been identified as a critical person in the development of the motivational climate in sport $[7,8,9]$. Through their interactions with athletes, coaches foster a motivational climate that can influence athletes' thoughts, feelings and actions in sport. In her research with high performance coaches, Kidman [10] found that many coaches recognised the importance of creating a positive environment:

“...if you create the right environment, then you can actually use more time more efficiently" (international netball coach) [10, p.100].

Jones and colleagues [2] also reported examples of elite coaches recognising the importance of developing a positive climate; e.g., UK Athletics coach, Peter Stanley, felt that in developing a positive training climate it was important to minimise athlete rivalry within his training squads:

Reviewers: $\quad$ Nic James (University of Wales Swansea, UK) Mike Voight (University of Southern California, USA) 
“...it's no good having friction in training sessions.... I don't have them compete with each other often in training... I don't want a pecking order to be established in training, as it can drain the competitiveness and motivation out of the athletes between the actual meets themselves" [2, p.80-81].

The purpose of this paper is to provide a synthesis of research concerning the motivational climate fostered by coaches that extends existing notions of the motivational climate beyond competence-focused goals to include other athletes' needs, such as autonomy and relatedness. We examine both the coaches' and athletes' perspectives on coaches' behaviour and the motivational climate in team and individual sports.

\section{MOTIVATIONAL CLIMATE}

The concept of motivational climate is used in this paper to represent situational influences on athletes such as the structure of sport activities (e.g., organisation of training sessions) and interpersonal interactions between coaches and athletes. To develop an understanding of the motivational climate and its influence on athletes it is useful to consider both coaches' and athletes' perspectives. Do coaches deliberately attempt to construct certain climates? If so, how are these created? How do athletes perceive and interpret coaches' behaviours? What influence does the perceived motivational climate have on athletes' development and performance?

A focus on athletes' views of the climate is consistent with dominant social cognitive perspectives employed to understand athletes' cognitions, affect and behaviours in sport [11 13]. These perspectives suggest that in order to understand the influence of situational factors such as the motivational climate on athletes, it is critical to understand the subjective meaning athletes attach to coaches' behaviours $[14,15]$. This meaning is developed through individuals' experiences in sport and their interpretations of those experiences. Individuals' perception and interpretation of the motivational climate in which they are operating influences their subsequent action $[14,16]$. For example, research by Smith and colleagues $[17,18]$ with youth sport coaches and athletes demonstrated that athletes who played for coaches whose behaviour was reflective of a motivational climate emphasising competence development (i.e., supportive and instructional comments) had positive post-season attitudes towards their coach, the sport, and team-mates regardless of win-loss record. Furthermore, these athletes were more likely to report a desire to continue playing for their coach the following season compared with athletes whose coaches exhibited less support and instruction.

Within social cognitive perspectives, situational influences are hypothesised to 'act through' athletes' perceptions of competence, autonomy, and relatedness [11 - 13]. Perceptions of the motivational climate influence the extent to which athletes feel competent, self-determined and connected with others in the sport context. A climate that fosters feelings of competence, self-determination and relatedness is purported to influence athletes' thoughts, feelings and behaviours such as choices, effort, persistence and enjoyment. Two approaches to examining the situational influences in sport have emerged in research. These are Achievement Goal theory [11, 12] and Self-Determination theory [13]. The work examining the motivational climate has predominantly been based on Achievement Goal theory and we discuss this literature first. Self-Determination theory is then used to frame additional research related to situational influences on athletes and we make the case for extending current notions of the motivational climate beyond the key 'need' of competence to additional needs of autonomy and relatedness. 


\section{ACHIEVEMENT MOTIVATION PERSPECTIVE}

Extending her research within an achievement motivation perspective in education settings, to sport settings Ames [1] contended that the ways in which coaches shape and structure the sport setting establishes a motivational climate that conveys certain goals to athletes. She suggested that through the design of practices, grouping of athletes, evaluations, rewards and recognition of athletes, coaches make certain cues and expectations salient. Ames [1] referred to competence-based, task and ego goals. A task goal is focused on improving one's level of competence and feeling a sense of mastery based on internalised standards of competence. An ego goal reflects an emphasis on demonstrating competence relative to others and feeling successful based on having exceeded the performances of others (especially if less effort than others was required).

In defining features of the climate that convey these competence goals, Ames [1] reflected on a number of questions (see Table 1). Coaches answering these questions with an emphasis on athlete learning, effort and personal improvement in competence are shaping and structuring the climate to convey a task goal to their athletes. Ames referred to this as a mastery motivational climate. If the answer to these questions emphasises demonstrating superior competence to others and a focus on normative standards of comparison, then an ego goal is being prioritised. Ames referred to this as a performance motivational climate.

Table 1. Features of Mastery and Performance Motivational Climates.

\begin{tabular}{lll} 
Questions & Mastery & Performance \\
\hline How is success defined? & $\begin{array}{l}\text { Improvement in personal } \\
\text { competence level }\end{array}$ & $\begin{array}{l}\text { Demonstrating competence } \\
\text { level superior to others }\end{array}$ \\
\hline & $\begin{array}{l}\text { Learning, effort, } \\
\text { competence improvement }\end{array}$ & $\begin{array}{l}\text { Performance outcomes and } \\
\text { favourable normative } \\
\text { comparisons of competence }\end{array}$ \\
\hline $\begin{array}{l}\text { How are mistakes viewed? } \\
\text { engage in the activities? }\end{array}$ & Part of learning & Learn new skills \\
$\begin{array}{l}\text { What does the } \\
\text { leader focus on? }\end{array}$ & Development, learning & $\begin{array}{l}\text { Demonstrate superior } \\
\text { competence }\end{array}$ \\
& & $\begin{array}{l}\text { Performance outcomes, } \\
\text { normative rankings } \\
\text { /comparisons }\end{array}$ \\
\hline
\end{tabular}

It is not only the motivational climate that conveys certain goals. Individuals also have a predisposition to adopt certain goals (i.e., goal orientation). Both goal orientation and the motivational climate are purported to interact to influence the goal adopted and resulting achievement behaviour [9]. Relatively little research has examined this interaction effect, but it has been suggested that the effect depends on the strength of the environmental cues, the athletes' goal orientation, and the outcome of interest [19]. The stronger the environmental cues (the motivational climate) relative to the goal orientation, the greater the likelihood of the motivational climate influencing the goal focus. Furthermore, the more situationallyspecific the achievement variable of interest (e.g., enjoyment) compared with dispositional variables (e.g., beliefs about the causes of success) the more likely that the motivational climate will be the best predictor [19]. Two studies that examined this relationship found that the motivational climate was the stronger predictor relative to goal orientations. In a study of elite female handball, perceived the motivational climate was a superior predictor (relative to goal orientation) of athletes' perceptions of performance improvement, satisfaction with 
performance and rating of the coach [20]. In a study of Winter Olympics athletes, Pensgaard and Roberts [21] found that the motivational climate (but not goal orientations) was a significant predictor of distress for these athletes.

\section{Athletes' perspectives}

Researchers have attempted to understand the influence of the motivational climate on athletes. A review of this research by Ntoumanis and Biddle [7] indicated that a mastery climate tends to be quite strongly associated with positive motivational outcomes such as athlete satisfaction, positive attitudes and intrinsic motivation. In contrast, a performance climate tends to be moderately associated with more negative outcomes such as worry and anxiety. More recent research has supported these findings. In a study with female adolescent volleyball players, for example, Newton et al [22] found that perceptions of a task-involving (i.e., mastery) climate were related to greater satisfaction with team participation and greater intrinsic motivation (based on greater effort, importance, enjoyment and interest ratings and lower pressure/tension ratings). In a study with male adolescent soccer and cricket players, Reinboth and Duda [23] found that athletes who perceived a performance motivational climate also reported greater reliance on sporting success to feel good about themselves (i.e., contingent self-worth) and were more likely to report indices of ill-being (such as physical exhaustion and physical symptoms including headaches, runny/congested nose and stiff/sore muscles). In addition, those athletes with a low perception of physical competence and who perceived that they were in a performance climate also reported the lowest levels of selfesteem of all the athletes in the study.

Relatively little research has examined elite athletes' perceptions of the motivational climate, but this limited research further supports an emphasis by coaches on competence development rather than performance outcomes. A case study of a former elite gymnast found that coaches and parents developed and reinforced a performance motivational climate. Several negative consequences were attributed to this climate, including competing while seriously injured, unhealthy eating practices and overtraining [24]. Winter Olympic athletes' perceptions of a performance motivational climate significantly predicted cognitive distress (e.g., uncertainty), distress associated with coach and team-mates, and total distress; whereas perceived mastery motivational climate was negatively associated with the coach and team-mates as sources of distress [21]. A study of elite female handball players found that a stronger perceived task-involving climate was associated with players reporting greater performance improvement, satisfaction with performance, as well as more positive views of their coach. However, a weak relationship emerged between perceptions of an egoinvolving climate and greater satisfaction with competitive results [20]. A study of elite college golfers, who perceived a task-involving climate, were less likely to report use of selfhandicapping in a competitive sport setting [25]. A study of Norwegian Olympic skiers found that they all reported a preference for a mastery motivational climate in training and felt that the coach played a significant role in determining the climate [8]. When asked to reflect on their experiences of the motivational climate as young athletes, these skiers felt that their coaches emphasised fun and that any performance focus in the climate came from interaction with their peers rather than being created by the coach. This finding suggests that there may have been sufficient focus on performance outcomes from the skiers themselves without any need (or desire) for the coach to emphasise such a focus. Rather, they preferred that the coach foster a mastery motivational climate. Other researchers have recognised that team-mates, peers and parents play a part in shaping the motivational climate in sport [26-28].

The research to date from the athlete's perspective indicates a relationship amongst 
motivational climate, affect and motivation. Specifically, an emphasis on learning and effort (a mastery climate) is associated with positive affective and motivational outcomes. These consequences of a mastery climate are predicted to lead to greater learning and performance [1]. However, relatively little is known regarding the causal effect of motivational climate on actual learning and performance (particularly in elite sport). One exception is the work of Theebom [29] who examined the relationship between the climate and skill development in a 3-week intervention as part of a youth sports programme. In one group, the instruction of martial arts was modified to reflect a mastery motivational climate while in a second group a more traditional climate (characterised by 'drilling') was employed. At the end of the intervention, it was found that children in the mastery climate (compared with those in the traditional instruction setting) reported greater enjoyment, perceived competence and intrinsic motivation; and were rated higher with regard to motor skill development. This study provides further evidence of benefits to be gained by adopting a mastery-focused motivational climate with respect to increased self-perceptions, affect, and motivation; as well as providing some initial evidence regarding a positive influence on learning and performance. Research is needed to examine further the influence of the motivational climate on actual learning and performance in different populations such as adolescents and elite athletes.

\section{Coaches' perspectives}

The focus to date on athletes' perspectives of the motivational climate is consistent with social cognitive theoretical frameworks. It is the meaning that athletes attach to their experiences (and specifically coaches' behaviour) that is critical for understanding situational influences on athletes. It is also important to understand the coaches' perspectives regarding the coaching process. How do coaches attempt to foster certain climates and the outcomes they are seeking? Do coaches recognise the importance of the motivational climate? Do they actively attempt to foster certain climates? If so, which climates? Based on recent research with high-performance coaches, it appears that at least some coaches do recognise the importance of the climate and their role in developing it $[2,10]$. These coaches focused on fostering a climate in which continuous learning was a central part. This is reminiscent of a mastery motivational climate. Research involving interviews with elite coaches [2, 10] provides evidence that they recognised the importance of creating a positive coaching environment in which learning was a critical component. This emphasis was reflected in the comments of New Zealand (NZ) international rugby coach Wayne Smith, "I am a coach that likes to learn ....I communicate that attitude to the players, making sure that they are open to new ideas" [10, p. 188].

These views from research support anecdotal reports from highly successful coaches such as the former UCLA men's basketball coach, John Wooden, and the former Australian Women's Hockey team coach, Richard Charlesworth. John Wooden's view of success, which formed the foundation of his approach to coaching, certainly appears to reflect a mastery view, "success is peace of mind that is the direct result of self-satisfaction in knowing that you did your best to become the best that you are capable of becoming" [30, p.170]. Charlesworth also emphasised the importance of developing a continuous learning environment in his work with the Australian Women's Hockey team:

By experimenting with different tactics, different formations, different combinations of players and different approaches to leadership, training and team management, the Hockeyroos created their own learning environment. [31, p.208] 


\section{Fostering a mastery climate}

Ames [1] provided clear (but challenging) strategies for fostering a mastery motivational climate and reducing a performance climate. These strategies included the design and structure of activities (e.g., drills and training sessions) to maximise variety, individual input, involvement, challenge and progress within flexible groupings; and interacting with athletes in ways that emphasise, recognise and reinforce individual input, improvement and progress. Researchers have not directly assessed the extent to which coaches deliberately construct the environment to reflect the features of a mastery motivational climate. However, research examining coach behaviour has shown that certain behaviours are more likely to be associated with athletes' perceptions of a mastery motivational climate. Instruction that provides information about how to improve - conveyed and reinforced with positive feedback - has been associated with athletes' perceptions of a mastery motivational climate [32]. Furthermore, research with a number of high-performance coaches has identified practices that reflect features of a mastery motivational climate. Gallimore and Tharpe's [33] investigation of John Wooden's coaching practices has demonstrated that Wooden worked to create opportunities for athletes to learn. They reported that Wooden did this by ensuring that his training sessions were highly organised, which included planning for needs of the individual as well as the group, and by providing a high frequency of individualised instruction to develop each player.

Jones and colleagues [2] also found that the coaches they interviewed promoted a climate where the emphasis was on learning. These researchers identified multiple ways in which coaches fostered learning including: focusing on individual development as an end in itself as well as for the benefit of the team; reflecting on how their coaching practices (in and out of the sporting arena) influenced athlete development, confidence and well-being; learning from the athletes; recognising the importance of working one-to-one within a group; being open, flexible and honest; and developing trust. Richard Charlesworth emphasized that mistakes should be considered learning opportunities [31] as did John Wooden:

"...the team that makes the most mistakes will probably win... mistakes come from doing, but so does success. The individual who is mistake-free is probably sitting around doing nothing. And that's a very big mistake." [30, p.73]

Theoretical conceptualisation of the motivational climate has focused on how situational cues emphasise certain goals, specifically task and ego goals, which are focused on the development and demonstration of competence. Researchers have found support, from both athletes and coaches, for a mastery motivational climate. In focusing on creating a motivational climate that fosters learning, however, it is important to consider more than just the development of athlete competence. Given that Ryan and Deci [34] have suggested that social environments supporting all three basic psychological needs (i.e., competence, autonomy and relatedness) will yield optimal human functioning characterised by motivation, growth and well-being, we will now consider a broader view of the motivational climate.

\section{BROADENING THE NOTION OF 'CLIMATE’}

In addition to developing athlete competence, there is growing evidence from research related to Self-Determination theory [13] to suggest that the climate should also foster athlete autonomy and relatedness (also referred to as belonging or social connectedness) [15]. Ryan and Deci $[13,34]$ proposed that if individuals' basic needs for competence, autonomy and relatedness are satisfied, then their motivation is likely to be intrinsic or self-determined (i.e., 
athletes value and freely engage in their sport, as opposed to possessing non self-determined motivation where they feel obligated or pressured to participate). Research has demonstrated that intrinsic motivation and self-determined motivation are important determinants of persistence and performance in sport [35]. The research related to autonomy and relatedness in sport from the perspectives of athletes and coaches is discussed separately in the following sections. Subsequently, there is a case example that demonstrates an integrated approach to fostering autonomy and relatedness with a high-performance international sports team.

\section{AUTONOMY}

Athletes who act with a sense of autonomy in sport engage in the activity for their own valued reasons and feel that they have freely chosen to be involved [13,34]. Fostering athlete autonomy is predicted to have a desirable impact on athletes' sport experiences, including performance [3]. In general, fostering autonomy implies that an individual in a position of authority (such as a coach) gives consideration to the athlete's perspective, provides choice and encourages involvement with decision-making [3].

\section{Athletes' perspectives}

An athlete's sense of autonomy has been associated with positive sporting outcomes and is influenced by the actions of coaches. A study conducted with college athletes demonstrated that democratic coaching behaviours were associated with greater perceived autonomy and intrinsic motivation [36]. Furthermore, studies examining athletes' well-being have demonstrated associations with autonomy support. Specifically, changes in gymnasts' well being (positive and negative affect, subjective vitality, and self-esteem) from pre- to postpractice varied with the extent to which athletes felt their autonomy was supported during practice [5]. In a longitudinal study of athlete well being, Reinboth and Duda [37] found that athletes who perceived an increase in the task-involving climate over the season also demonstrated an increase in satisfaction of autonomy, competence and relatedness. In turn, an increase in perceptions of autonomy and relatedness was related to increased subjective vitality. In contrast, some research has indicated a link between the actions of coaches and negative outcomes in sport (e.g., lower levels of moral functioning). In a study of youth soccer players, athletes' perceptions of a performance motivational climate (with limited autonomy opportunities) were related to low levels of moral functioning [38]. The link between performance climate and moral functioning is consistent with other research in youth soccer that has revealed a significant relationship between a performance climate and attitudes toward rough play and cheating [39], low levels of sportsmanship [40] and multiple indices of moral functioning in sport [41].

\section{Coaches' perspectives}

Recent research suggests that many coaches do value and attempt to foster athlete autonomy. Reflecting on his coaching of the Australian Olympic men's athletics relay team, Mallet [42] indicated that he actively sought suggestions, opinions and feedback from athletes in a deliberate attempt to foster athletes' sense of autonomy. The coaches interviewed by Kidman [10] all adopted an empowering approach, which is similar to autonomy support - "a coach who empowers athletes facilitates their learning but does not control it" [10, p.17). For example, Mike McHugh (New Zealand international women's basketball coach) emphasised allowing players to have input and accept ownership of their team's effectiveness in stating that, "this is not divorcing my responsibility as a coach but allowing the players a greater role in the decision-making process, having them accept a greater responsibility for the team's 
effectiveness" [10, p149]. Jones and colleagues [2] also found that several of the coaches they interviewed tried to consider the athletes' point of view and be athlete-centered such as Hope Powell's (England international women's football coach) efforts in planning training sessions to consider how athletes might respond to the sessions and try to make them fun for the players.

\section{Fostering autonomy}

Mageau and Vallerand [3] proposed a model of the coach-athlete relationship based on SelfDetermination Theory [13] in which they identified features of the coach-athlete relationship that should foster competence, autonomy and relatedness. Their model emphasises fostering autonomy with relatively little discussion on fostering competence or relatedness. They drew from educational and psychological research to support the behaviours they proposed to influence autonomy. These behaviours included: providing choice and a rationale for tasks, limits and rules, including providing opportunities for athletes to take initiative; avoiding guilt-inducing or controlling statements and minimising ego-involvement; and inquiring about and acknowledging athletes' feelings.

Research with coaches indicates that coaches actively support athletes' autonomy by emphasising the development of athletes' understanding of their sport through the use of questioning, providing opportunities for decision-making and listening to athletes. Jones and colleagues [2] indicated that the coaches in their study provided a rationale for tasks by indicating that it was not only important to tell players how to do things, but also why they are done. This approach was summed up by one of their interviewees who stated that "you can't go out there and pull strings. I've got to have decision makers out there. I think the coach really is a facilitator that gives players their team understanding" [Lois Muir, NZ international netball coach p. 88-89]. Kidman's [10] research also revealed strategies that coaches used to foster autonomy. For example, Ruth Aitken (New Zealand international netball coach) used questioning and posing problems to encourage her athletes to think and understand why they do what they do rather than just telling them the answers. It can also involve creating situations that require decision-making and allowing time and opportunity to make decisions. These research findings are supported by anecdotal accounts of coaching such as from Australian hockey coach Richard Charlesworth, who reported that,

...every [player] was encouraged to behave like a leader. That didn't mean giving orders, but it meant taking responsibility for getting their jobs right and for the team working co-operatively. It meant dealing with problems as they arose and taking responsibility for them [31, p.207].

\section{RELATEDNESS}

Despite increased research and interest in the tenets of Self-Determination theory [13], relatively little is known about the situational factors associated with relatedness or the potential associated thoughts, feelings and actions. The variety of terms and definitions that have been used to capture relatedness (e.g., relatedness [3, 34], belonging [43, 44] and social connectedness [45]) highlight the difficulty in producing a single definition of the term. However, the essence of relatedness is a concern about connections with others and the quality of our interpersonal relationships. Relatedness is characterised by both a psychological sense of attachment or bond with others and quality interpersonal relationships that reflect perceived care for and from others, a sense of stability or security in the relationship and regular contact with those others [45]. 
When considering the importance of a concept such as relatedness for coaches, it is useful to consider that the coaching process is by definition a social process. At a bare minimum, it involves a relationship between a coach and an athlete and some form of interpersonal interaction [46]. How this relationship and interaction takes place is likely to influence athletes' perceptions of relatedness, which may in turn influence their thoughts, feelings and actions in sport.

\section{Athletes' perspectives}

There have been few direct examinations of the relationships among coaches' actions, athletes' perception of relatedness and sporting outcomes. However, insight can be gained from related research as well as research from education settings. For example, Mageau and Vallerand [3] drew from research that focused primarily on parental involvement to demonstrate support for their proposal that coach involvement was critical for athletes' sense of relatedness. They demonstrated a positive association among adult involvement (including caring and support) with young athletes' participation, enjoyment and motivation. In their interviews with 12 former elite athletes, all of whom were Olympic medallists, Jowett and Cockerill [47] found that these athletes characterised their relationships with their coaches through closeness, which included liking, trust, respect and belief in each other. In addition, they also noted that their relationships with their coach were characterised as including coorientation, such as shared knowledge, goals and understanding; and helping transactions, such as encouragement, support and consistency in the relationship. The characteristics identified by these athletes included many elements of relatedness and it is likely that these athletes would have felt a sense of relatedness with their coach. Furthermore, in interviews with Olympic skiers from Norway, Pensgaard and Roberts [8] found that the athletes desired a training environment that was caring and supportive (i.e., fostered relatedness).

Several recent studies examining tenets of Self-Determination theory in sport have also demonstrated relationships amongst coaching behaviours, relatedness, and motivation and well being. Hollembeak and Amorose [36] found that greater positive feedback from the coach was associated with athletes' perceived relatedness, which was in turn associated with greater intrinsic motivation. Reinboth and colleagues [6] revealed that male adolescent athletes who perceived greater coach social support were more likely to report greater perceived relatedness. Reinboth and Duda [37] discovered that a task-involving climate was associated with an increase in athletes' sense of relatedness, which in turn was related to increased athlete well-being. This recent research suggests that relatedness is associated with important sporting outcomes, such as motivation and well being; and that coaching practices are associated with an athlete's sense of relatedness.

Research in education settings also supports these relationships among relatedness and quality of children's functioning at school, as well as the teacher's role in fostering relatedness [48 - 51]. For example, a greater sense of relatedness at school has been associated with desirable educational outcomes such as perceived academic competence, positive affect toward school, adaptive self-regulation and achievement. Goodenow [49] found that middle school students (11-15 years) who reported greater perceived relatedness compared with those who indicated lower school relatedness were less likely to be absent or late for school. These students were also likely to be more confident about success at school, value schoolwork more, work harder (teacher rating) and actually obtain better grades at school. In addition, these students were more likely to choose to stay at the same school the following year, when there was a choice to move to a new school. In two studies of secondary school, physical education students, Ntoumanis [52] and Standage and colleagues 
[53] found that students' relatedness was positively related to self-determined forms of motivation for physical education, which was in turn associated with intentions to be physically active in the future. Research has also demonstrated that the quality of the relationship with the teacher plays an important role in children's sense of relatedness and subsequent functioning at school $[4,51]$. Just as the teacher is a central person in developing the climate experienced in school, so too is the coach a central person in the sport motivational climate. But do coaches give consideration to athlete relatedness?

\section{Coaches' perspectives}

Relatively little is known about the extent to which coaches consider relatedness in their coaching. However, excerpts from research with high-performance coaches demonstrate that some coaches do appear to consider athlete relatedness. Jones and colleagues [2] reported that Graham Taylor (English football coach) "repeatedly emphasised the need for a coach to 'connect' with his or her athletes, with the ability to gain the latter's 'trust' and 'respect' being regarded as crucial" [2, p.28]. Caring about their athletes was considered integral to establishing a positive, relaxed working climate and these coaches believed that a caring climate was an effective way to maximise other outcomes such as athlete determination and effort [2].

In a case study of a professional football coach in the United Kingdom, Potrac and colleagues [54] found that the coach emphasised the use of frequent (but deserved) praise as important for developing a 'positive' learning environment and that the coach believed that players responded better to coaches who encouraged and told them what they were doing well. They reported that the coach was cautious of scolding players, particularly in front of other players, because he felt that this could jeopardise his working relationship with the player. It seems that the coach was focused on creating a social bond between himself and his players, with an important part of this bond being the players' respect for him as a person [54]. Although not specifically addressing relatedness, the coach in this case study clearly recognised the importance of the nature and quality of the relationship he sought to create and maintain with his athletes.

Fostering positive relationships amongst athletes is also likely to contribute to relatedness and is therefore useful for developing a productive motivational climate in sport. The research on team cohesion and team building is likely to provide a useful contribution to understanding this process, but this is beyond the scope of this article (see [55] for a review of team cohesion research). It is useful to note, however, that in bringing together the concepts and propositions from theory related to cohesion and relatedness it will be necessary to provide a clear conceptualisation of the associations between relatedness, cohesion, and the motivational climate. Vallerand [15] has suggested that cohesion is a social contextual factor that should influence perceptions of relatedness and, in turn, motivation. Preliminary correlational evidence supports this proposition [56], but the causal nature of this relationship has not been verified. The relationship between cohesion and the motivational climate has not been conceptualised and questions remain regarding whether cohesion is an antecedent, a consequence, or an integral part of certain motivational climates.

\section{Fostering relatedness}

Mageau and Vallerand [3] proposed that coach involvement was central to fostering athlete relatedness, but their discussion of coach involvement was based on research and implications for coaches relating to autonomy supportive behaviours and a rather 'loose' conceptualisation of relatedness as coach/parent involvement and support. Again recent research in sport and education is useful in elaborating on how coaches might foster athlete 
relatedness. Olympic athletes have reported that having the freedom to be themselves was important to the development of a productive motivational climate [8]. This feeling of freedom to be oneself could be viewed as a consequence of secure and stable relationships amongst their team-mates and with their coach - a feature of relatedness. Potrac and colleagues [54] found that careful and deliberate use of deserved praise and minimal scolding, particularly in a public setting, were important coaching behaviours to foster a strong social bond between coach and athletes. The coaches in Jones and colleagues' [2] research indicated strategies such as developing trust, being open minded, and considering the athlete as a person (rather than only an athlete) were important for developing a strong relationship with their athletes. Preliminary evidence from research being conducted with the New Zealand international netball team has highlighted that players' sense of belonging appears to be central to their desire and motivation to learn, develop and perform [57].

Research from education regarding the development of caring school environments and fostering relatedness amongst school students can provide further insight into how coaches might foster relatedness amongst their athletes. In their work examining caring school communities, Battistich and colleagues [58] found that the characteristic of a caring approach included teacher practices such as warmth and support toward students; promotion of cooperation rather than competition; eliciting students' thinking and discussion; emphasising pro-social values; and minimising the use of extrinsic controls such as points and prizes. Wentzel [59] found that teachers who were considered by their students to be 'caring' were those who cared about what they taught and communicated in a democratic manner that was open and reciprocal rather than focused on content. These 'caring' teachers were also equitable in their treatment of students, conveying expectations for students as a person and a learner that recognised their unique potential. They also respected the students expressing warmth and approval through both formal and informal evaluations with the students.

The nature of the relationships between coach and athlete (and among athletes) is critical to fostering relatedness. Developing relationships through getting to know, trust and respect each other is likely to foster the care and security in interpersonal relationships that are central to a sense of relatedness. Therefore, in considering how coaches create a motivational climate that fosters relatedness coaches might reflect on the following questions:

- How does the coaching process ensure that all athletes have opportunities to feel a sense of relatedness?

- Are the same opportunities for quality interactions provided regardless of athletes' ability level, gender, race/ethnicity, religious or social background?

- Which athletes are being excluded and why?

- What types of social interactions and relationships do coaches model and reinforce?

\section{CASE EXAMPLE: FOSTERING AUTONOMY \& RELATEDNESS IN} A HIGH-PERFORMANCE TEAM

The New Zealand national rugby team (i.e., the 'All Blacks') has a remarkable $73 \%$ winning percentage in over 400 international 'test' matches since 1904. In 2004, a new coaching staff (head coach, Graham Henry, and his assistant coaches - Wayne Smith and Steve Hansen) introduced a radical change to the team culture and coaching philosophy within the All Black team [60]. These changes reflected the coaches' desire to deliberately foster both autonomy and relatedness (although they did not use these specific psychological terms). Under the general catch cry of 'Better People Make Better All Blacks,' the All Blacks coaching staff in 2004-2005 set out to explicitly teach and emphasise player autonomy and relatedness [60- 
63]. Their logic for doing so was both utilitarian (i.e., to increase performance and enhance the team's ability to win test matches) and utopian (i.e., help their players develop 'life skills' for a life after they retire from professional rugby). In terms of performance, their coaching approach would appear to have been a spectacular success - in 2004-2005, the All Blacks won 20 of $23(87 \%)$ test matches against top opponents [64]. This example suggests that fostering autonomy and relatedness need not be at the expense of quality performance and in fact performance may well be improved. So what did the All Black coaching staff do to develop and emphasise player autonomy and relatedness?

\section{Autonomy}

With respect to autonomy, head coach Graham Henry stated: "We try to develop self-reliance and leadership to make them better people."'[61] Furthermore, Henry observed that one of the highlights of their first season with the team (2004) was the joy of witnessing, "...those guys taking leadership. Having responsibility in certain areas. That was a real positive in developing our performance." [65] Henry and his assistant coaches deliberately provided their players with the opportunity to have:

“... a lot of input into what we're doing and we have empowered the players to voice their opinions so we can improve.... Players are happy when they are stimulated... When we talk about them as 'better people,' we're talking about people who are self-reliant and have self-leadership, take responsibility for the team and have collective ownership." [60]

This autonomy, self-reliance and leadership approach was not just confined to the senior or more experienced players, according to Wayne Smith, one of the assistant coaches, who was quoted as saying:

“...even young guys... If you can influence them early... their confidence and ability to say what they think rather than hide away because they're a new All Black, then they're going to be good players" [63]

Indeed, this approach of empowering younger, less experienced players was strongly supported by the experienced players who agreed with the need for an All Black leadership group. Here is a quote from Richie McCaw, the All Blacks vice-captain:

"It's just that sometimes in the past you get into a team - especially the All Blacks - and everyone looks to everyone else to see what we're doing, and everyone else for responsibility. And then it all comes back to the captain who carries a lot of the load. So what the coaches are trying to do is spread the load a little bit, if you have a core group of players who have worked a few things out in terms of how the team are going to run." [66].

\section{Relatedness}

As one method for enhancing player relatedness (and also autonomy), the All Blacks coaching staff encouraged senior players to take a lead in helping new players. Tana Umaga, the All Blacks captain, has been quoted as saying:

“...we try to duplicate the family environment by making friends and never leaving them alone. It's when you're alone that you start feeling lonely and think about home. You just make sure they have someone there to talk to." [67] 
Graham Henry emphasised the importance of camaraderie, that players, “...need to enjoy each other's company so there's quite a lot of social activity... it gets them closer and the camaraderie is important".[61] Finally, assistant coach Steve Hansen highlighted the performance benefit of developing relatedness within the team and has been quoted as follows:

"The more people we can have who are their real self and not wanting to be an ideal self or what the public wants them to be, the better; because they'll do that when they're playing and perform better as a result." [62]

This example emphasises fostering relatedness amongst players, but the encouragement of player input and leadership by coaches is also likely to foster relatedness between coach and athlete as they get to know, trust and respect each other.

\section{CHALLENGES}

This paper has shown that research from both athletes and coaches suggests that a climate with an emphasis on learning has positive outcomes and involves developing competence, supporting autonomy and fostering relatedness. While examining this research, three challenges have been identified for coaches. First, the challenge for coaches is to become critically reflective and consider what climate they create, the impact it has on all athletes, how it has been created, and why it has been created. A second challenge concerns the current tendency to promote a mastery motivational climate over a performance climate. It would be useful to understand more about how coaches 'balance' or deal with the pressures for performance outcomes - from their employer, sponsors and athletes themselves - while retaining a mastery focus (particularly with elite athletes). Third, this paper emphasised the consideration of athletes' needs as part of the coaching process. At times, however, this may mean that coaches may need to 'juggle' consideration of athletes' needs with the demands placed on them as coaches (such as changes in the composition of the team and/or coaching staff). A greater understanding of how these pressures are dealt with would provide useful insight into the complexities of the coaching process.

Three challenges have been identified for researchers. A central challenge is to examine the direct influence of motivational climates on learning and performance. The research reviewed here demonstrates a relationship between motivational climate and athletes' thoughts, feelings and actions, but relatively little is known about whether a mastery motivational climate leads to actual learning and/or improved performance (or how this might be achieved). Virtually nothing is known about the impact on learning and performance of climates fostering autonomy and relatedness in sport. Second, it is important to remember that coach-created climates - the focus of this paper - are embedded within a wider socio-cultural climate of the club, organisation, society and sport. How does this wider climate impact on coaches' ability to foster a learning environment? Finally, the climate is dynamic and thus there may be new personnel, and different contexts and situations. Little is known about how these socio-cultural factors influence coaches' ability to foster a climate that emphasises learning.

\section{CONCLUSION}

Coaching is a complex social process. This paper brings together research from two theoretical approaches to extend our understanding of the multidimensional nature of the 
motivational climate and its implications for coaching. Ames [1] viewed the motivational climate as the situationally emphasised goal perspectives operating in achievement settings. This conceptualisation of the climate has led to considerable research that has helped us to develop a better understanding of the motivational significance of the structures and interactions involved in coaching, but it is a view that is linked to only one specific goal of action - developing and/or demonstrating competence [14]. This goal forms a critical objective for sport participation, but research indicates that there appears to be more to developing a motivational climate that can foster athletes' learning than simply focusing on competence. Both athletes and coaches appear to appreciate the potential benefits that fostering autonomy and relatedness can have on athletes' development. Fostering athletes' psychological needs for autonomy and relatedness appear to be as important as competence, thus they should be considered in the development of a broader view of the motivational climate for coaching.

\section{REFERENCES}

1. Ames, C., Achievement Goals, Motivational Climate, and Motivational Processes, in: Roberts, G.C., ed., Motivation in Sport and Exercise, Human Kinetics, Champaign, IL, 1992, 161-176.

2. Jones, R., Armour, K. \& Potrac, P., Sports Coaching Cultures: From Practice to Theory, Routledge, London, 2004.

3. Mageau, G. A. \& Vallerand, R. J., The Coach-Athlete Relationship: A Motivational Model, Journal of Sports Sciences, 2003, 21, 883-904.

4. Furrer, C. \& Skinner, E., Sense of Relatedness as a Factor in Children's Academic Engagement and Performance, Journal of Educational Psychology, 2003, 95(1), 148-162.

5. Gagne, M., Ryan, R. M. \& Bargmann, K., Autonomy Support and Need Satisfaction in the Motivation and Well-Being of Gymnasts, Journal of Applied Sport Psychology, 2003, 15, 372-390.

6. Reinboth, M., Duda, J. L. \& Ntoumanis, N., Dimensions of Coaching Behaviour, Need Satisfaction, and the Psychological and Physical Welfare of Young Athletes, Motivation and Emotion, 2004, 28(3), 297-313.

7. Ntoumanis, N. \& Biddle, S. J. H., A Review of Motivational Climate in Physical Activity. Journal of Sport Sciences, 1999, 17, 643-665.

8. Pensgaard, A. M. \& Roberts, G. C., Elite Athletes' Experiences of the Motivational Climate: The Coach Matters, Scandinavian Journal of Medicine and Science in Sport, 2002, 12, 54-59.

9. Treasure, D. C., Enhancing Young People's Motivation in Youth sport: An Achievement Goal Approach, in: Robert, G.C., ed., Advances in Motivation in Sport and Exercise, Human Kinetics, Champaign, IL, 2001, 79100 .

10. Kidman, L., Athlete-Centred Coaching: Developing Inspired and Inspiring People, Innovative Print, Christchurch, New Zealand, 2005.

11. Nicholls, J. G., Conceptions of Ability and Achievement Motivation, in: Ames, R. and Ames, C., eds., Research on Education in Motivation: Student Motivation (Vol. 1), Academic Press, Orlando, FL, 1984, 3968.

12. Nicholls, J. G., The Competitive Ethos and Democratic Education, Harvard University Press, Cambridge, MA, 1989.

13. Ryan, R. M. \& Deci, E. L., Self-Determination Theory and the Facilitation of Intrinsic Motivation, Social Development, and Well-Being, American Psychologist, 2000, 55(1), 68-78.

14. Roberts, G. C., Understanding the Dynamics of Motivation in Physical Activity: The Influence of Achievement Goals on Motivational Processes, in: Robert, G.C., ed., Advances in Motivation in Sport and Exercise, Human Kinetics, Champaign, IL, 2001, 1-50.

15. Vallerand, R. J., Toward a Hierarchical Model of Intrinsic Motivation, Advances in Experimental Social Psychology, 1997, 29, 271 -360. 
16. Maehr, M., Meaning and Motivation: Toward a Theory of Personal Investment, in: Ames, R. and Ames, C., eds., Research on Motivation in Education: Student Motivation, Academic Press, Orlando, FL, 1984, 115207.

17. Smith, R., Smoll, F. \& Curtis, B., Coaching Effectiveness Training: A Cognitive-Behavioural Approach to Enhancing Relationship Skills in Youth Sport Coaches. Journal of Sport Psychology, 1979, 1, 59-75.

18. Smith, R. E., Smoll, F. \& Curtis, B., Coaching Behaviours in Little League Baseball, in: Smoll, F. and Smith, R.E., eds., Psychological Perspectives on Youth Sports, Hemisphere, Washington, DC, 1978, 173-201.

19. Duda, J. L. \& Hall, H. K., Achievement Goal Theory in Sport: Recent Extensions and Future Directions, in: Singer, R., Janelle, C. and Hausenblas, H., eds., Handbook of Research in Sport Psychology, 2nd ed., John Wiley \& Sons, New York, 2001, 417-443.

20. Balaguer, I., Duda, J. L., Atienza, F. L. \& Mayo, C., Situational and Dispositional Goals as Predictors of Perceptions of Individual and Team Improvement, Satisfaction and Coach Ratings Among Elite Female Handball Teams, Psychology of Sport and Exercise, 2002, 3, 293-308.

21. Pensgaard, A. M. \& Roberts, G. C., The Relationship Between Motivational Climate, Perceived Ability and Sources of Distress Among Elite Athletes, Journal of Sports Sciences, 2000, 18, 191-200.

22. Newton, M., Duda, J. \& Yin, Z., Examination of the Psychometric Properties of the Perceived Motivational Climate in Sport Questionnaire-2 in a Sample of Female Adolescents, Journal of Sports Sciences, 2000, 18, 275-290.

23. Reinboth, M. \& Duda, J. L., The Motivational Climate, Perceived Ability, and Athletes' Psychological and Physical Well-Being, The Sport Psychologist, 2004, 18, 237-251.

24. Krane, V., Greenleaf, C. A. \& Snow, J., Reaching for Gold and the Price of Glory: A Motivational Case Study of an Elite Gymnast, The Sport Psychologist, 1997, 11(1), 53-71.

25. Kuczka, K. K. \& Treasure, D. C., Self-Handicapping in Competitive Sport: Influence of the Motivational Climate, Self-Efficacy, and Perceived Importance, Psychology of Sport and Exercise, 2005, 6, 539-550.

26. White, S. A., Duda, J. L. \& Hart, S., An Exploratory Examination of the Parent-Initiated Motivational Climate Questionnaire, Perceptual and Motor Skills, 1992, 75, 875-880.

27. White, S. A., Goal Orientation and Perceptions of the Motivational Climate Initiated by Parents, Pediatric Exercise Science, 1996, 8, 122-129.

28. Vazou, S., Ntoumanis, N. \& Duda, J. L., Peer Motivational Climate in Youth Sport: A Qualitative Inquiry, Psychology of Sport and Exercise, 2005, 6, 497-516.

29. Theeboom, M., De Knop, P. \& Weiss, M. R., Motivational Climate, Psychological Responses, and Motor Skill Development in Children's Sport: A Field-Based Intervention Study, Journal of Sport and Exercise Psychology, 1995, 17, 294-311.

30. Wooden, J. R., A Lifetime of Observations and Reflections On and Off the Court, McGraw-Hill, New York, 1997.

31. Charlesworth, R., The Coach: Managing for Success, MacMillan, Sydney, Australia, 2001.

32. Smith, S. L., Fry, M. D., Ethington, C. A. \& Li, Y., The Effects of Female Athletes' Perceptions of Their Coaches' Behaviours on Their Perceptions of the Motivational Climate, Journal of Applied Sport Psychology, 2005, 17, 170-177.

33. Gallimore, R. \& Tharp, R., What a Coach can Teach a Teacher, 1975-2004: Reflections and Reanalysis of John Wooden's Teaching Practices, The Sport Psychologist, 2004, 18(2), 119-137.

34. Ryan, R. \& Deci, E., An Overview of Self-Determination Theory: An Organismic-Dialectical Perspective, in: Deci, E. and Ryan, R., eds., Handbook of Self-Determination Research,University of Rochester Press, Rochester, New York, 2002, 3-36.

35. Vallerand, R. J. \& Rousseau, F. L., Intrinsic and Extrinsic Motivation in Sport and Exercise, in: Singer, R., Janelle, C. and Hausenblas, H., eds., Handbook of Sport Psychology, 2nd ed., Wiley, New York, 2001, 389416.

36. Hollembeak, J. \& Amorose, A. J., Perceived Coaching Behaviours and College Athletes' Intrinsic Motivation: A Test of Self-Determination Theory, Journal of Applied Sport Psychology, 2005, 17(1), 20-36. 
37. Reinboth, M. \& Duda, J. L., Perceived Motivational Climate, Need Satisfaction and Indices of Well-Being in Team Sports: A Longitudinal Perspective, Psychology of Sport and Exercise, 2006, 7, 269-286.

38. Kavussanu, M. \& Spray, C., Contextual Influences on Moral Functioning of Male Youth Footballers, The Sport Psychologist, 2006, 20, 1-23.

39. Boixados, M., Cruz, J., Torregrosa, M. \& Valiente, L., Relationships Among Motivational Climate, Satisfaction, Perceived Ability, and Fair Play Attitudes in Young Footballers, Journal of Applied Sport Psychology, 2004, 16, 301-317.

40. Miller, B., Roberts, G. \& Ommundsen, Y., Effect of Motivational Climate on Sportspersonship Among Competitive Male and Female Football Players, Scandinavian Journal of Medicine \& Science in Sports, 2004, 14, 193-202.

41. Ommundsen, Y., Roberts, G., Lemyre, P. \& Treasure, D., Perceived Motivational Climate in Male Youth Soccer: Relations to Socio-Moral Functioning, Sportspersonship and Team Norm Perceptions, Psychology of Sport \& Exercise, 2003, 4, 397-413.

42. Mallet, C., Self-Determination Theory: A Case Study of Evidence-Based Coaching, The Sport Psychologist, $2005,19(4), 417-429$

43. Baumeister, R. F. \& Leary, M. R., The Need to Belong: Desire for Interpersonal Attachments as a Fundamental Human Motivation, Psychological Bulletin, 1995, 117(3), 497-529.

44. Goodenow, C., The Psychological Sense of School Membership Among Adolescents: Scale Development and Educational Correlates, Psychology in the Schools, 1993, 30, 79-90.

45. Allen, J. B. \& Petrie, K. C., Connecting Through Physical Education: A Position Paper Exploring Social Connectedness, Journal of Physical Education New Zealand, 2005, 38(1), 81-94.

46. Lyle, J., Sports Coaching Concepts, Routledge, London, 2002.

47. Jowett, S. \& Cockerill, I. M., Olympic Medallists' Perspective of the Athlete-Coach Relationship, Psychology of Sport and Exercise, 2003, 4, 313-331.

48. Anderman, L. H., Classroom Goal Orientation, School Belonging and Social Goals as Predictors of Students' Positive and Negative Affect Following the Transition to Middle School, Journal of Research and Development in Education, 1999, 32(2), 89-103.

49. Goodenow, C., Classroom Belonging Among Early Adolescent Students: Relationships to Motivation and Achievement, Journal of Early Adolescence, 1993, 13(1), 21-43.

50. Roeser, R. W., Midgley, C. \& Urdan, T. C., Perceptions of the School Psychological Environment and Early Adolescents' Psychological and Behavioral Functioning in School: The Mediating Role of Goals and Belonging, Journal of Educational Psychology, 1996, 88(3), 408-422.

51. Ryan, R. M., Stiller, J. D. \& Lynch, J. H., Representations of Relationships to Teachers, Parents, and Friends as Predictors of Academic Motivation and Self-Esteem, Journal of Early Adolescence, 1994, 14(2), 226-249.

52. Ntoumanis, N., A Self-Determination Approach to the Understanding of Motivation in Physical Education, British Journal of Educational Psychology, 2001, 71(2), 225-242.

53. Standage, M., Duda, J. \& Ntoumanis, N., A Model of Contextual Motivation in Physical Education: Using Constructs from Self-Determination and Achievement Goal Theories to Predict Physical Activity Intentions, Journal of Educational Psychology, 2003, 95(1), 97-110.

54. Potrac, P., Jones, R. \& Armour, K., 'It's All About Getting Respect': The Coaching Behaviors of an Expert English Soccer Coach. Sport, Education, and Society, 2002, 7(2), 183-202.

55. Carron, A., Hausenblas, H. \& Eys, M., Group Dynamics in Sport, 3rd ed., Morgantown, WV: Fitness Information Technology, Morgantown, WV, 2005.

56. Allen, J. B., The Perceived Belonging in Sport Scale: Examining Validity, Psychology of Sport and Exercise, 2006, 7, 387-405.

57. Cassidy, T., Potrac, P. \& Allen, J., Examining the Developmental Experiences of Elite Athletes Using a Social Theory of Learning, Paper presented at the World Congress of AIESEP (International Association of Physical Education in Higher Education), Jyväskylä, Finland, 2006. 
58. Battistich, V., Solomon, D., Watson, M. \& Schaps, E., Caring School Communities, Educational Psychologist, 1997, 32(2), 137-151.

59. Wentzel, K., Student Motivation in Middle School: The Role of Perceived Pedagogical Caring, Journal of Educational Psychology, 1997, 89(3), 411-419.

60. Long, D., Henry: He's the Leader of the Pack, Sunday News, 2005, July 17, 22.

61. Donaldson, M., There Won’t be Any Mate Against Mate, Sunday Star-Times, 2005, July 31, B4.

62. Mirams, C., Cop it Sweet, Sunday Star-Times, 2004, November 21, B8.

63. Mirams, C., Winning Mind Games and Clearing the Clutter Seen as Key to Smith, Sunday Star-Times, 2004, November 28, B5.

64. Http://www.AllBlacks.com, Retrieved April 21, 2006.

65. Harding, G., World's No. 1 Team: The All Blacks, New Zealand Rugby World, 2005, December-January, 15.

66. Harding, G., All Black Test Captain No. 60: In Waiting, New Zealand Rugby World, 2004, November, 15.

67. Umaga, T., New Zealand Press Association, 2006, January 11. Http://www.AllBlacks.com, Retrieved April 21, 2006. 
